\title{
Mutation detection using ENDO I: Application to disease diagnostics in humans and TILLING and Eco-TILLING in plants
} Karine Triques ${ }^{1}$, Elodie Piednoir ${ }^{1}$, Marion Dalmais ${ }^{1}$, Julien Schmidt ${ }^{1}$, Christine Le Signor ${ }^{3}$, Mark Sharkey ${ }^{2}$, Michel Caboche ${ }^{1}$, Bénédicte Sturbois ${ }^{1}$ and Abdelhafid Bendahmane*1

Address: ${ }^{1}$ Unité Mixte de Recherche en Génomique Végétale, 2 rue Gaston Crémieux, CP5708, 91057 Evry Cedex, France, ${ }^{2}$ University of Massachusetts Medical School, Worcester, Massachusetts, USA and '3Unité Mixte de Recherche en Génétique et Ecophysiologie des Légumineuses, Domaine d'Epoisses, 21110 Bretenières, France

Email: Karine Triques - karine.triques@interieur.gouv.fr; Elodie Piednoir - elodie.Piednoir@evry.inra.fr; Marion Dalmais - dalmais@evry.inra.fr; Julien Schmidt - schmidt@evry.inra.fr; Christine Le Signor - lesignor@epoisses.inra.fr; Mark Sharkey - mark.sharkey@umassmed.edu; Michel Caboche - caboche@evry.inra.fr; Bénédicte Sturbois - sturbois@evry.inra.fr; Abdelhafid Bendahmane* - bendahm@evry.inra.fr

* Corresponding author

Published: 23 April 2008

BMC Molecular Biology 2008, 9:42 doi:10.1186/1471-2199-9-42

This article is available from: http://www.biomedcentral.com/l47I-2199/9/42

(C) 2008 Triques et al; licensee BioMed Central Ltd.

This is an Open Access article distributed under the terms of the Creative Commons Attribution License (http://creativecommons.org/licenses/by/2.0), which permits unrestricted use, distribution, and reproduction in any medium, provided the original work is properly cited.

\begin{abstract}
Background: Most enzymatic mutation detection methods are based on the cleavage of heteroduplex DNA by a mismatch-specific endonuclease at mismatch sites and the analysis of the digestion product on a DNA sequencer. Important limitations of these methods are the availability of a mismatch-specific endonuclease, their sensitivity in detecting one allele in pool of DNA, the cost of the analysis and the ease by which the technique could be implemented in a standard molecular biology laboratory.
\end{abstract}

Results: The co-agroinfiltration of ENDOI and $\mathrm{p} / 9$ constructs into $\mathrm{N}$. benthamiana leaves allowed high level of transient expression of a mismatch-specific and sensitive endonuclease, ENDOI from Arabidopsis thaliana. We demonstrate the broad range of uses of the produced enzyme in detection of mutations. In human, we report the diagnosis of the GI69IA mutation in Leiden factor- $V$ gene associated with venous thrombosis and the fingerprinting of HIV-I quasispecies in patients subjected to antiretroviral treatments. In plants, we report the use of ENDOI system for detection of mutant alleles of Retinoblastoma-related gene by TILLING in Pisum sativum and discovery of natural sequence variations by Eco-TILLING in Arabidopsis thaliana.

Conclusion: We introduce a cost-effective tool based on a simplified purification protocol of a mismatch-specific and sensitive endonuclease, ENDOI. Especially, we report the successful applications of ENDOI in mutation diagnostics in humans, fingerprinting of complex population of viruses, and in TILLING and Eco-TILLING in plants.

\section{Background}

Scanning DNA sequences for mutations and polymorphisms is an analytic tool in a broad range of disciplines.
However, identification of such mutations and polymorphisms in long stretches of DNA and in large numbers of samples by direct sequencing is not a trivial exercise. Sev- 
eral mutation detection techniques based on the physical properties of single stranded DNA or heteroduplex DNA [1-5] have been described. Among such methods are conformation sensitive gel electrophoresis (CSGE) [3], denaturing gradient gel electrophoresis (DGGE) [6], constant denaturing capillary electrophoresis, (CDCE) [7], Temperature Gradient Capillary Electrophoresis (TGCE) [8], single strand conformation polymorphism (SSCP) [2] and denaturing high-performance liquid chromatography (DHPLC) [1]. Other methods exploit chemicals like groove binders or chemicals that cleave single strand DNA at the mismatch site in heteroduplex DNA [9].

Single strand specific nucleases have also been used to cleave heteroduplex DNA at the mismatch site [10-13]. Among them, CEL I is a mismatch specific endonuclease [14] that is widely used for reverse genetics in plants, animals and bacteria [15-22] and for disease diagnostic in human such as cancers related to BRCA1 $[23,24]$. Enzymatic mutation detection is advantageous over other popular mismatch detection systems, like TGCE and DHPLC $[8,25-27]$ because mismatch specific endonucleases allow to screen large stretches of DNA without reducing diagnostic sensitivity or specificity, while at the same time providing information about the location of the mutation. However, many mismatch specific cleavage enzymes were reported to cleave preferentially certain types of mismatches, display low sensitivity or lead to a high background $[10,11,20,28,29]$.

Previously, we reported the biochemical analysis of five S1 type nucleases from Arabidopsis thaliana. We demonstrated that one of them, ENDO1, is a mismatch specific endonuclease, which cleaves with a high efficiency all types of mismatches and has a high sensitivity, detecting one allele in pool of sixty [30]. Here, we report a very simple protocol for the expression and the preparation of ENDO1. Especially, we report the use of ENDO1 in combination with universal labelled primers as a cost-effective tool for mutation diagnostics in humans, plants and viruses.

\section{Results \\ Rapid preparation of ENDOI}

ENDO1 is expressed at low level in Arabidopsis during plant senescence [31]. In order to facilitate the expression of the protein, the ENDO1 ORF was inserted between the $35 \mathrm{~S}$ promoter and the transcriptional terminator of CaMV in the binary vector pBIN61 (Figure 1a) [30]. The construct was transformed into Agrobacterium and co-agroinfiltrated into $N$. benthamiana leaves in the presence of the p19 protein of tomato bushy stunt virus (TBSV), that prevents the onset of post-transcriptional gene silencing (PTGS) in infiltrated tissues and allows a high level of transient expression (Figure 1a) [32]. As negative control a

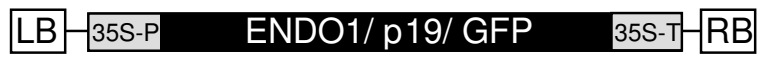

b

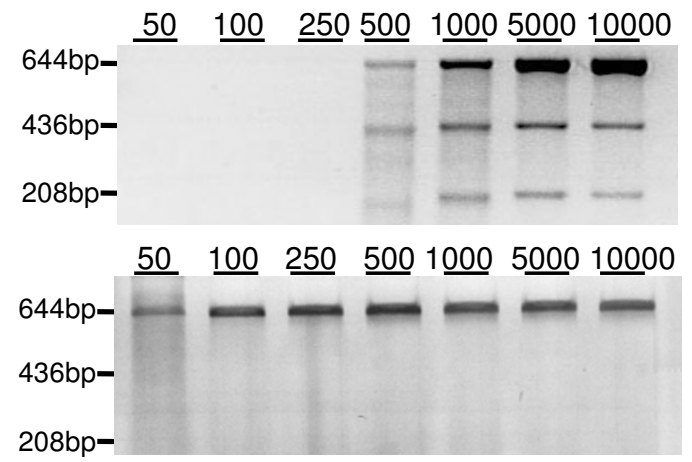

\section{Figure I}

Expression and analysis of ENDOI activity. (a) Construction bearing, ENDOI, TBSV pl9 or GFP ORFs. The box indicates the ORF of the protein to be expressed, cloned between the $35 \mathrm{~S}$ promoter (35S-P) and the transcriptional terminator (35S-T) of CaMV. LB and RB indicate the left and right border of the T-DNA respectively. (b) Heteroduplex DNA was created based on two clones that differ in single base insertion at position 436 bp of the 644 bp test PCR product. Heteroduplex DNA was digested with the tobacco protein extract derived from leaves co-agroinfiltrated with ENDOI and TBSV p 19 constructs (upper picture) after 50, $100,250,500,1000,5000$ and 10000-fold dilution and analyzed on $1.5 \%$ standard agarose gel. Protein extract from leaves co-agroinfiltrated with TBSV p 19 and GFP, instead of ENDOI construct, was used as a negative control (lower picture).

the plants were also agroinfiltrated with a construct expressing the green fluorescent protein (GFP).

Ten grams of agroinfiltrated leaves were homogenized and cleared by centrifugation in the absence and in the presence of $30 \%$ ammonium sulphate. Ammonium sulphate was then added to $80 \%$ final concentration in the supernatant and the pelleted proteins were resuspended in buffer containing 50\% glycerol, dialysed against the same buffer and stored at $-80^{\circ} \mathrm{C}$.

To test whether ENDO1 obtained from this simplified purification protocol is active we tested the protein extract on heteroduplex DNA created from two clones that differ by a single base insertion (Figure $1 \mathrm{~b}$ ). In this experiment we predicted that if the ENDO1 preparation contains a mismatch specific endonuclease, the heteroduplex DNA will be cleaved at the mismatch site releasing two bands of 
208 bp and 436 bp (Figure 1b). Duplex DNAs were incubated with dilutions of ENDO1 or GFP protein extracts. ENDO1 led to the predicted digestion product and as expected the GFP control showed undetectable mismatch specific cleavage activity (Figure $1 \mathrm{~b}$, lower picture). As shown for His-tag purified ENDO1 [30] and CEL I [20], at high concentration (50 to 250 fold dilution, Figure 1b), ENDO1 presented double strand DNAse activity and digested the entire fragments. From this biochemical analysis we concluded that ENDO1 simplified purification led to an active enzyme and the test mutation was detected at dilutions ranging from 500 to 10000 fold (Figure 1b, upper picture). Based on this analysis and duplicates of this experiment (data not shown), we estimate that the amount of enzyme produced from 10 grams of agroinfiltrated leaf material, and used at 10000 fold dilution, is enough to carry more than a million mismatch detection tests.

\section{Detection of G I 69 IA mutation in factor $V$}

We tested ENDO1 prepared as above in mutation diagnostics in humans. As a proof of concept, we investigated the detection of the factor V G1691A mutation associated with venous thrombosis $[33,34]$. Genomic DNA was extracted from individuals harboring or not the G1691A mutation and analyzed using ENDO1 system. To reduce the diagnostic cost, we combined the ENDO1 mismatch detection system with the use of labelled universal primers in the amplification of the target sequence (Table 1). In this analysis we expected that if the 611 bp heteroduplex DNA fragment of factor $\mathrm{V}$ is cleaved at the mismatch site, two bands of $300 \mathrm{bp}$ and $311 \mathrm{bp}$ would be released (Figure 2a). Results obtained from both 700 and 800 channels of the LI-COR4300 show that ENDO1 recog- nizes the G1691A mutation (Figure 2b, lane 1 and 2). No cleavage was observed on PCR product obtained from a control person not carrying the G1691A mutation (Figure $2 \mathrm{~b}$, lane 3 and 4 ). The experiment was repeated three times with similar results (data not shown). As expected the presence of G1691A mutation was confirmed by sequencing in the patient heterozygote for the mutation (Figure 2c). Because mutation detection relies on heteroduplex formation between two alleles, detection of the G1691A mutation at the homozygous state will require mixing genomic DNA from a control individual not harbouring the mutation with that of an individual to be tested.

\section{Fingerprinting of HIV-I quasispecies}

Human immunodeficiency virus type 1 (HIV-1) present in infected individuals has been described as quasispecies of related but distinct viruses [35-38]. When the selective pressure of antiretroviral therapy is exerted on such a population, drug-resistant mutants may emerge and consequently lead to treatment failure $[35,37]$. The objective of this work was to assess the HIV-1 quasispecies evolution during different treatments. Direct sequencing of PCR amplified HIV-1 DNA fragment from an infected individual will detect only predominant mutations. Detailed analysis of the HIV quasispecies using sequencing would require the cloning of PCR products and systematic sequencing of individual clones. A list of alternative technologies have been also tested to identify minor HIV drugresistant populations [39-43].

Previously we demonstrated that ENDO1 can detect rare alleles in pools of DNA [30]. Thus, we tested the use of ENDO1 system as a fingerprinting protocol to assess the

Table I: Primers used to amplify target loci

\begin{tabular}{|c|c|c|}
\hline Targets & Primer name & Primer sequence \\
\hline \multirow[t]{2}{*}{ Factor V } & MI3F-FV Forward & cacgacgttgtaaaacgac ttaattggttccagcgaaagc \\
\hline & MI3R-FV Reverse & ggataacaatttcacacagg tccaataccaacagacctgg \\
\hline \multirow[t]{2}{*}{ Reverse Trans. } & MI3F-RT Forward & cacgacgttgtaaaacgac taggacctacacctgtcaacataa \\
\hline & MI3R-RT Reverse & ggataacaatttcacacagg cttctgtatgtcattgacagtcca \\
\hline \multirow[t]{4}{*}{ RBR exon I0-II } & RB-INI Forward & ggagcagtcagaataagcggaatg \\
\hline & RB-INI Reverse & taaccaagcccacatcgacgtcatc \\
\hline & RB-IN2 Forward & cacgacgttgtaaaacgac ggctacaattatctcagcagataag \\
\hline & RB-IN2 Reverse & ggataacaatttcacacagg gtcctcttactttccggttgctgaa \\
\hline \multirow[t]{4}{*}{ RBR exon $14-17$} & RB-2NI Forward & tgaagaagacgccctgtttggcatc \\
\hline & RB-2NI Reverse & gttgcttaagtgaagaagccgatct \\
\hline & RB-2N2 Forward & cacgacgttgtaaaacgac tgagtgtcttggaaaatgattacga \\
\hline & RB-2N2 Reverse & ggataacaatttcacacagg aggcaaggaaggcacaggaggcaat \\
\hline \multirow[t]{2}{*}{ BAC FI5K9 } & Tail-At Forward & cacgacgttgtaaaacgac gctgattatgggatgatgatatt \\
\hline & Tail-At Reverse & ggataacaatttcacacagg aaaaagcagcgagttataggtttac \\
\hline
\end{tabular}

Targets: corresponding GenBank accession numbers are Human coagulation factor V (Factor V, Z99573), HIV-I Reverse Transcriptase (Reverse

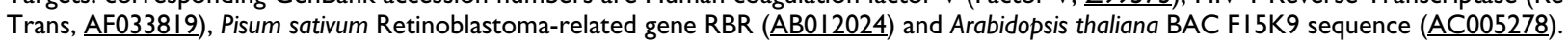
Primer sequence: in bold are indicated MI3 forward and reverse universal tails; in simple text is indicated the part of the primer specific to the target sequence. 
a

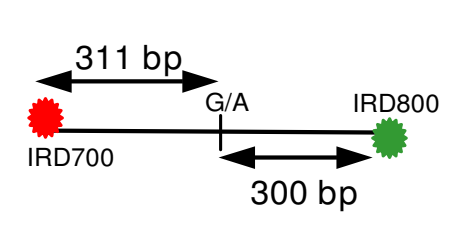

b

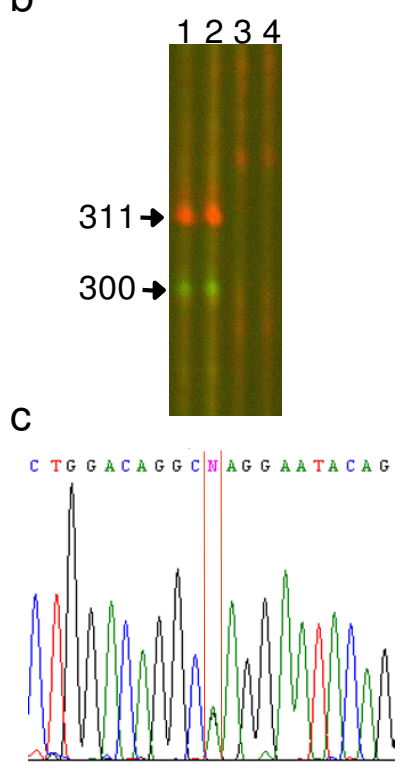

d

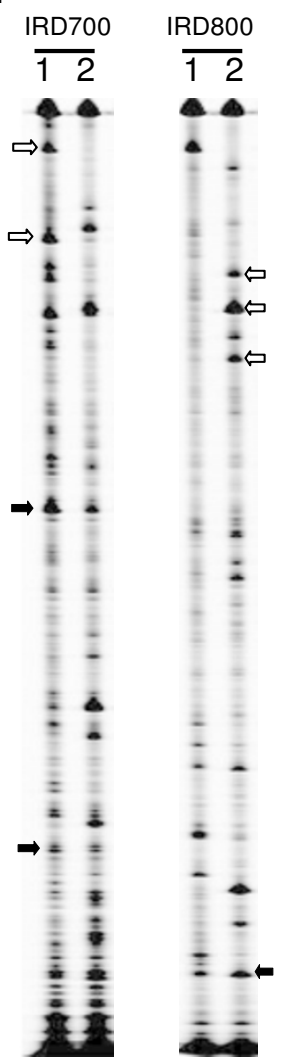

Figure 2

Detection of G I 69 I A mutation in factor $V$ in human and Fingerprinting of HIV-I quasispecies. (a) Schematic representation of $6 \mathrm{II}$ bp DNA fragment of factor $V$ indicating GI69IA mutation associated with venous thrombosis. The red and green dots indicate the position of IRD700 and IRD800-labelled primers, respectively. (b) Genomic DNA was extracted from leg hairs of a non-carrying (lane 3 and 4) and heterozygous individual for the GI69IA mutation (lane I and 2). The 6I I bp DNA fragment corresponding to the region harboring the mutation was $P C R$ amplified, denaturated/renaturated prior to digestion with ENDOI and analyzed on on LI-COR4300 DNA Analyzer. Sizes of the digested fragments are indicated on the left. (c) Chromatogram of the sequence of the human Factor $V$ fragment from heterozygous individual showing the GI69IA mutation. (d) Genomic DNAs were extracted from peripheral blood mononuclear cells of an HIV-I infected patient before (lane I) and after 48 weeks of antiretroviral therapy (lane 2). DNA fragment of 843 bp coding for the reverse transcriptase gene of HIV-I was PCR amplified, denaturated/renaturated prior to digestion with ENDOI and analyzed on LI-COR4300 DNA Analyzer. The collected image from both channels is shown (IRD700 and IRD800 channels). Examples of bands of invariant intensity that indicate stable mutations are indicated by filled arrow. Examples of bands indicating mutations that either appeared or were lost upon treatment are indicated by empty arrows.

HIV-1 quasispecies evolution during different treatments. We focused the analysis on the sequence variation in a DNA fragment of 843 bp coding for the reverse transcriptase gene of HIV-1. Genomic DNAs were extracted from peripheral blood mononuclear cells of an HIV-1 infected patient before (Figure 2d, lane 1) and after 48 weeks of antiretroviral therapy (Figure $2 \mathrm{~d}$, lane 2). The reverse transcriptase gene was PCR amplified and analysed using ENDO1. Two different patterns of bands, representing fingerprints of HIV-1 quasispecies at each time, were observed (Figure 2d). Comparing the overall patterns and changes in intensity of particular fragments allowed the identification of mutations that either appeared or were lost upon treatment (Figure 2d, empty arrows). Bands of invariant intensity indicate stable mutations (Figure 2d, filled arrows).

\section{Exploitation of ENDOI in TILLING}

TILLING (Targeting Induced Local Lesions IN Genomes) method combines the induction of a high number of random mutations with mutagens like Ethyl Methane Sulfonate (EMS) and mutational screening systems to discover induced mutations in sequence DNA targets [44]. This reverse genetic strategy encompasses all types of organisms as plants, animals, bacteria, without being subjected to the genome size $[15-19,45,46]$.

To test whether ENDO1, purified using the simplified protocol, in combination with universal primers is efficient in TILLING, we screened 4717 M2 families of Pisum sativum-EMS mutagenized population (Dalmais et al., unpublished data) for induced mutations in the Retinoblastoma-Related gene, RBR. The RBR protein is wellknown as a regulator of cell division, differentiation and endoreduplication in plants [47]. So far, the use of insertion mutants to investigate the roles of RBR in plant development has been restricted, due to the gametophytic lethality [48]. Two DNA fragments of 1078 bp and 972 bp of RBR were PCR amplified using nested PCR in combination with universal primers (Table 1; Figure 3a). PCR products were digested with ENDO1 and analysed on LICOR4300 gels as described above (Figure 3b). From 1078 bp and 972 bp amplicons we obtained 34 and 16 mutants, respectively (Figure 3c). From this, 3 were intronic, 17 were silent and 30 were missense mutations. No nonsense mutants were recovered, likely because of their gametophytic deleterious effects [48].

To evaluate the robustness of ENDO1 purified using the simplified protocol, in combination with universal primers for mutation detection, RBR TILLING was carried out with conventional method based on Ni-Column-purified ENDO1 and gene specific primers. A similar number of mutants were identified (data not shown). Based on the TILLING of RBR and other targets (data not shown) we 
a

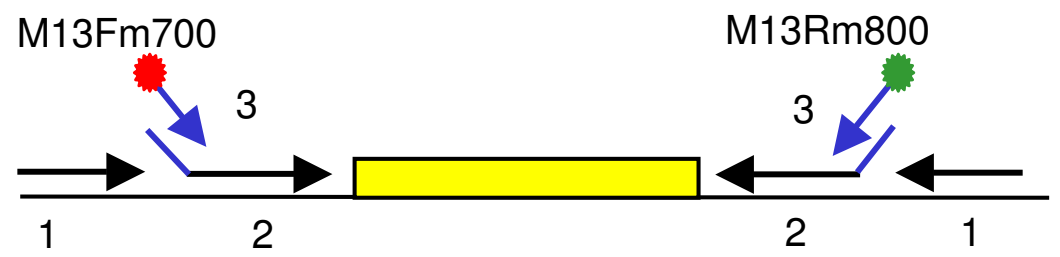

b
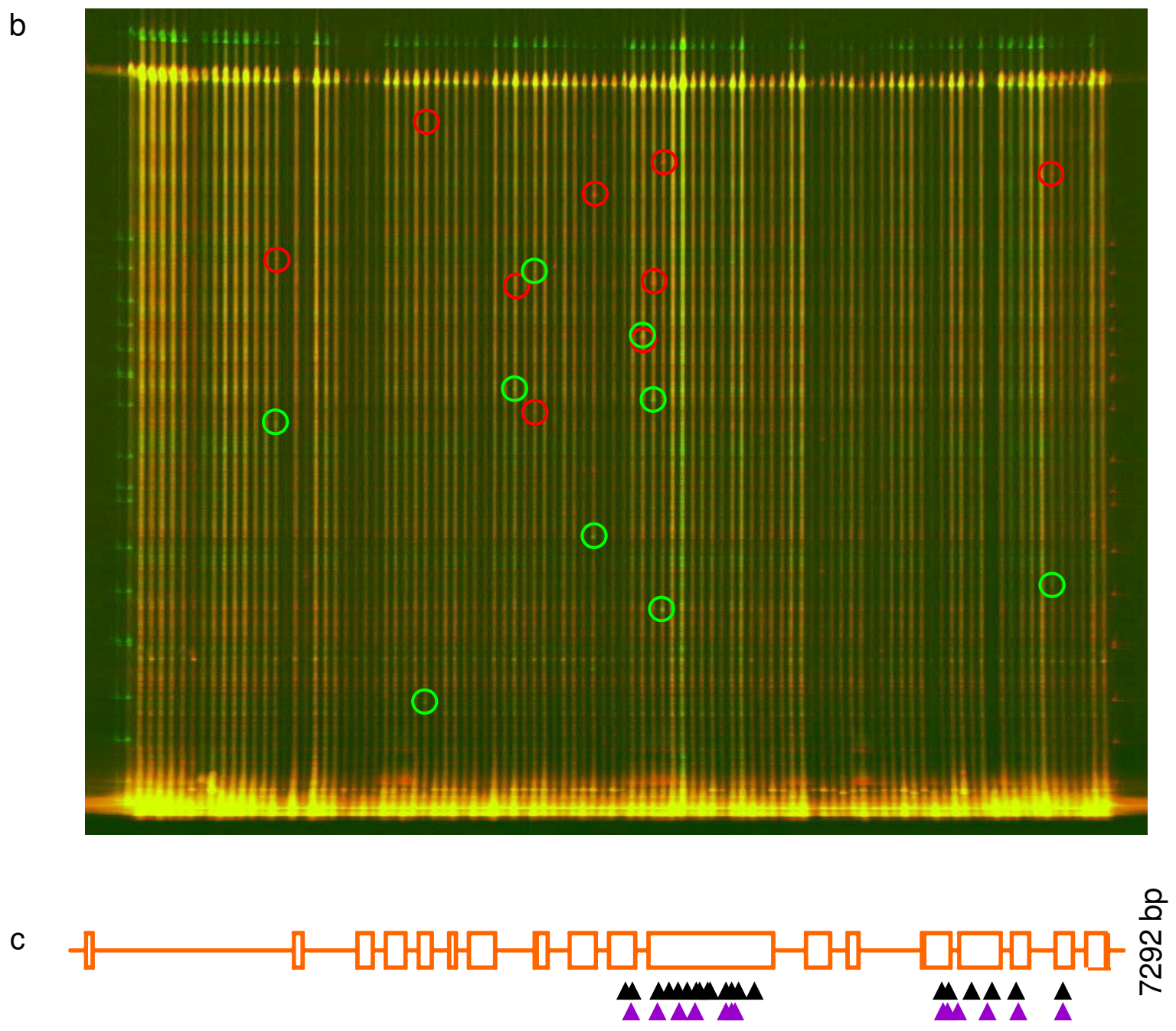

\section{Figure 3}

TILLING using ENDOI. (a) Universal primers Tilling strategy. Targets were amplified by PCR with gene specific primers (black arrows I), followed by a nested-PCR with internal gene specific (black parts of arrows 2) primers containing a universal MI3 tail (blue parts of arrows 2), in combination with IR DYE-labeled universal MI3 primers (blue arrows 3); the red and green dots indicate the position of IRD700 and IRD800-labelling, respectively. The sequence of the primers are indicated in Table I (b) Example of a RBR Tilling screen on 8-fold pooled pea DNA. The gel images represent the superposed image from the IRD700 and IRD800 channels. The sizes of the cleavage products (circled) from the 2 dyes-labeled DNA strands (red or green) add up to the size of the full-length PCR products (top of the gel). PCR artifacts are distinguishable from true mutants by yellow points (red and green added) as they appear of the same size in both channels. The size of the cleavage product (sizing ladder in the first and last lanes) indicates approximately where the SNP is located in the fragment. (c) Graphic representation of mutations identified in two regions of RBR gene. This drawing was made using the PARSESNP program [54], which maps the mutation on a gene model to illustrate the distribution of mutations. The purple and black triangles represent silent and missense mutations, respectively. The black lanes indicate the two tilled amplicons. 
concluded that the ENDO1 simplified protocol is suitable for high throughput TILLING screen.

\section{Exploitation of ENDOI in Eco-TILLING}

ECoTILLING is a means to determine the extent of natural sequence variation across many germplasms, enabling both SNP discovery and haplotyping [22]. This technique is now applied to rice, maize, lotus, poplar [49], Brassica, zebrafish, Drosophila, Caenorhabditis and human [50], indicating its broad applicability.
In Arabidopsis thaliana, we analysed natural sequence variations within a DNA fragment of 456 bp (Figure 4a) using the ENDO1 system (Figure 4c) and sequence analysis (Figure 4b), in two Arabidopsis ecotypes, Columbia and Landsberg. We expected that if the 456 bp heteroduplex DNA fragment, created from Columbia and Landsberg pooled genomic DNAs (lane 1), is cleaved at the mismatch sites, four bands of 325, 274, 182 and $131 \mathrm{bp}$ would be released. Results obtained from both channels 700 and 800 of the LI-COR4300 show that ENDO1 recog- a

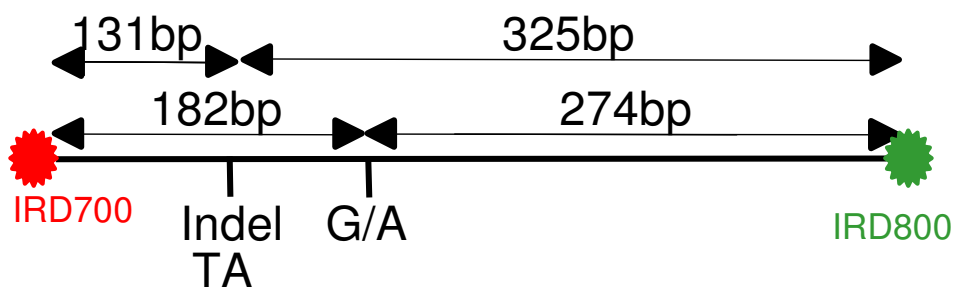

b
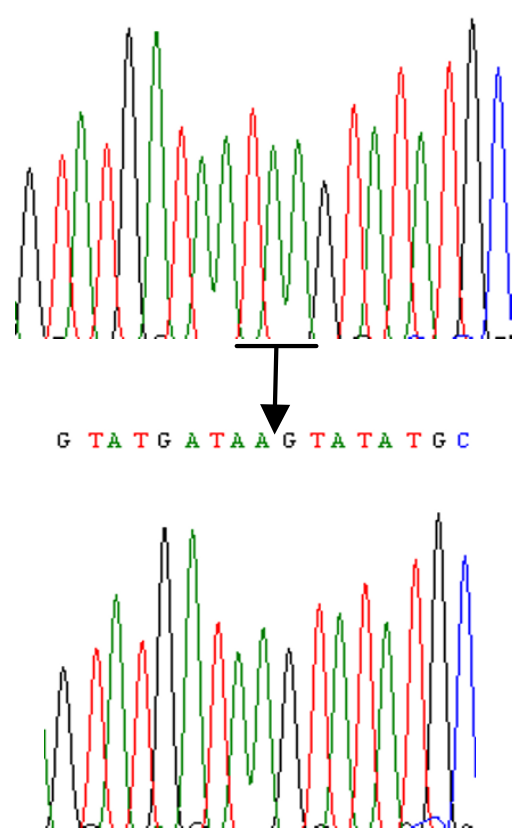

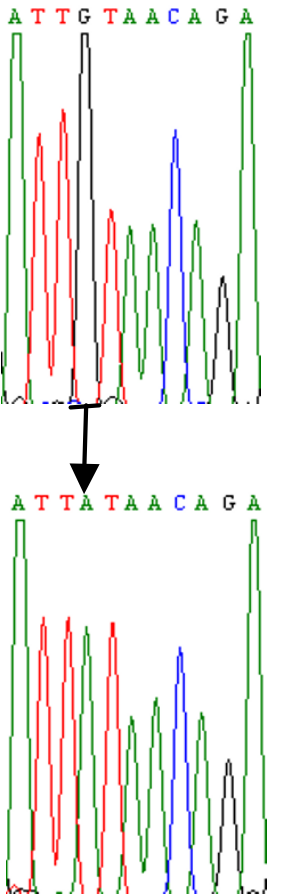

C

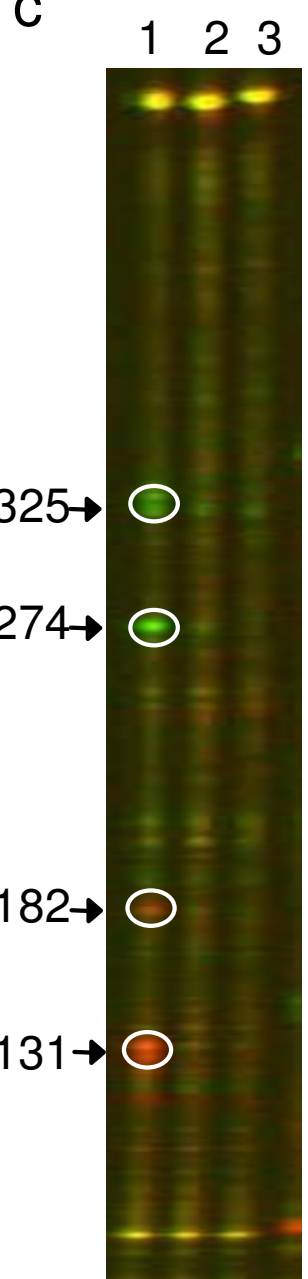

Figure 4

Eco-TILLING using ENDOI. (a) Schematic representation of a 456 bp genomic DNA fragment of Arabidopsis thaliana showing two sequence polymorphisms, 3-base INDEL and the G to A substitution, between Columbia and Landsberg ecospecies.(b) The 456 DNA fragment was PCR amplified using the primers indicated in Table I. Heteroduplex DNA is prepared by mixing equimolar amounts of the two PCR products, generated from Columbia and Landsberg ecospecies, heating to denature the DNA followed by cooling to renature it. Lane I indicates heteroduplex DNA. Lane 2 and 3 indicate homoduplex DNA generated from Columbia and Landsberg ecospecies, respectively. Homo and heteroduplex DNAs were digested with ENDOI and analyzed on LI-COR4300 DNA analyzer. Expected band sizes are indicated on the left of the panel. (c) DNA sequencing chromatograms surrounding the 3-base INDEL (Left panel and underlined) and the G to A substitution (Right panel and underlined) between Columbia (upper sequence) and Landsberg (lower sequence) ecospecies. 
nizes, with a high specificity the three base pair INDEL and the $\mathrm{G}$ to A substitution (Figure 4c, lane 1). No cleavage was observed on PCR product obtained from the control Columbia and Landsberg-homoduplex DNAs (Figure $4 \mathrm{c}$, lane 2 and 3, respectively). The obtaining of four bands indicates that ENDO1 cleaves the DNA fragments partially. This characteristic of ENDO1 enhances the potential of the system, because it is able to detect sequence variation in a DNA fragment carrying multiple mutations in a single reaction.

\section{Discussion}

Mutation detection is often an expensive and time-consuming obstacle to many molecular genetic applications including reverse genetics and clinical diagnostics. In this work we describe an enzymatic mutation detection technique based on ENDO1. We focused our work on the main limitation of any enzymatic mutation detection system, the production of a mismatch specific endonuclease. CEL I is the most commonly used endonuclease in TILLING and EcoTILLING in plants and animals [15$19,21,22,45]$. Three protocols are reported for the purification of CEL I from celery stalks. The highly purified enzyme is prepared from $105 \mathrm{~kg}$ of celery stalks and a more simplified protocol use $7 \mathrm{~kg}$. Both protocols use a series of chromatography purifications steps requiring special equipments and skills in biochemistry. A more simplified protocol was reported [20] that use $0.5 \mathrm{~kg}$ of store-bought celery stalks. However, the minimum information on the name of the celery variety and the age of the plants to be used in the purification are missing, which renders the quality of produced enzyme uneven.

In this work, the co-agroinfiltration of ENDO1 and p19 constructs into $N$. benthamiana leaves allowed high level of transient expression. ENDO1 represented at least 6\% of total proteins (data not shown) and from 10 grams of plant material, we routinely obtain enough enzyme to carry out more than a millions mismatch detection tests. The crude purified ENDO1 was found to be stable, allowing at least 4 months storage at $-20^{\circ} \mathrm{C}$. For longer period storage we recommend to purify His-Tagged ENDO1 on Ni-NTA agarose beads as described previously [20]. The His-tag purified ENDO1 was found to be very stable, allowing at least two years storage at $-80^{\circ} \mathrm{C}$, one year storage at $-20^{\circ} \mathrm{C}$ and more than four months storage at $4^{\circ} \mathrm{C}$.

Several new techniques of mutation scanning based on microchips and/or sequencing or re-sequencing of a given genome are currently being developed [51]; however, these technologies yet have in common the major drawback of their cost. Such tools, despite their outstanding potential for mutation scanning, are now likely to be restricted for such applications to big laboratories specialised in sequencing or genotyping. On the other hand, using ENDO1 system, we demonstrated its universality as a low-cost strategy for easy high-throughput diagnostic of genetic mutations in different genomes, including those incompletely sequenced like pea. In humans, the ENDO1 system permitted the diagnosis of the well-known genetic mutation, G1691A in Factor V gene, which is often associated with activated protein $\mathrm{C}$ resistance that is a common risk factor for venous thrombosis [33]. In viruses, we described a fingerprinting protocol to assess the HIV-1 quasispecies evolution during different treatments. We showed that the detection of quasispecies using universal primers with two PCR-rounds or using specific primers in one PCR-round gave the same results (data not shown). The natural progression of viral species within HIV-1 infected patients and/or the correlation of the appearance of quasispecies with the resistance to certain antiretroviral could be essential for clinical survey. In plants, we demonstrated the use of ENDO1 in combination with universal primers to decrease further the cost of the screening in TILLING and Eco-TILLING, two strategies that require high throughput screening protocols.

The Agrobacterium transient-expression assay could be used not only to produce (at low cost) large amounts of ENDO1, but also to over-express other nucleases for which the expression in bacteria is toxic or require posttranslational modifications. Initial attempts to express ENDO1 and CEL I in E. coli were unsuccessful and when we succeeded, the expressed proteins showed no DNase activity (data not shown).

\section{Conclusion}

The ENDO1 preparation protocol described in this work does not require any particular equipment or skills and could be implemented in any standard molecular biology research laboratory. The produced ENDO1 was successfully used in mutations diagnostics in different genomes. In humans, the ENDO1 system permitted the diagnosis of the well-known genetic mutation in Factor $\mathrm{V}$ gene, which is often associated with venous thrombosis. In viruses, we described a fingerprinting protocol to assess the HIV-1 quasispecies evolution during different treatments. In plants, we demonstrated the use of ENDO1 in combination with universal primers to decrease further the cost of TILLING and Eco-TILLING.

\section{Methods}

\section{Overexpression of ENDOI}

pBIN35S-ENDOI construct was described previously [52]. Agrobacterium transient overexpression in Nicotiana benthamiana was performed as described previously [53] except that the cells were co-infiltrated into $N$. benthamiana leaves in presence of Agrobacterium harbouring pBIN61-p19 construct [32]. Agroinfiltrated plants were 
incubated for at least 60 to 96 hours in the green house before protein extraction.

\section{Purification of ENDOI}

Ten grams of agroinfiltrated leaves were homogenized in $10 \mathrm{ml}$ buffer containing $0.1 \mathrm{M}$ Tris- $\mathrm{HCl} \mathrm{pH} 8,200 \mu \mathrm{M}$ phenylmethylsulphonyl fluoride (PMSF), $0.125 \mathrm{mM} \beta$ mercaptoethanol and $10 \%$ of glycerol and cleared by centrifugation at $3,000 \times \mathrm{g}$ for $30 \mathrm{~min}$. Ammonium sulphate was added to the supernatant to the final concentration of $30 \%$ and the samples incubated on ice for 1 hour were centrifuged at $30,000 \times \mathrm{g}$ for $30 \mathrm{~min}$. Ammonium sulphate was added to the supernatant to $80 \%$ final concentration and the proteins were precipitated by centrifugation as above. The pellet was resuspended in $500 \mu \mathrm{l}$ of dilution buffer ( $50 \mathrm{mM}$ Tris-HCl pH 8, Glycerol $50 \%, 100 \mu \mathrm{M}$ PMSF), dialysed against the same buffer and stored at $-80^{\circ} \mathrm{C}$.

\section{PCR amplification and mutation detection}

In the TILLING screen, target loci were PCR-amplified using nested-PCR and universal primers. The first PCR amplification is a standard PCR reaction using target-specific primers [28]. One microlitre of the first PCR served as a template for the second nested PCR amplification, using a mix of gene-specific inner primers carrying a universal M13 tail (Table 1), in combination with M13 universal primers, M13F700 (CACGACGTTGTAAAACGAC) and M13R800 (GGATAACAATTTCACACAGG), labelled at the 5 'end with infra-red dyes IRD700 and IRD800 (LI-COR ${ }^{\circledast}$, Lincoln, Nebraska, USA), respectively. This PCR was carried out with each primers at $0.1 \mu \mathrm{M}$, using the following 2 steps cycling program: $94^{\circ} \mathrm{C}$ for $2 \mathrm{~min}, 10$ cycles at $94^{\circ} \mathrm{C}$ for $15 \mathrm{sec}$, primers specific annealing temperature for 30 sec and $72^{\circ} \mathrm{C}$ for $1 \mathrm{~min}$, followed by 25 cycles at $94^{\circ} \mathrm{C}$ for $15 \mathrm{sec}, 50^{\circ} \mathrm{C}$ for $30 \mathrm{sec}$ and $72^{\circ} \mathrm{C}$ for $1 \mathrm{~min}$, then a final extension of $5 \mathrm{~min}$ at $72^{\circ} \mathrm{C}$. The PCR amplification of factor $\mathrm{V}, \mathrm{HIV}-1$ reverse transcriptase and Arabidopsis BAC $15 \mathrm{~K} 9$ DNA fragment was carried out using only the second PCR conditions described above using $30 \mathrm{ng}$ of genomic DNA as template. Mutation detection, in nonpurified PCR products, was carried out as described previously [30] except that the crude extracted enzyme was used at 10000 fold dilution and $0.6 \mu \mathrm{l}$ of ENDO1-digestion products were loaded on the gel using disposable paper membrane combs (The Gel Company, San Francisco, USA).

\section{Authors' contributions}

KT developed ENDO1 preparation, performed factor V mutation detection and Eco-TILLING. EP and BS set up ENDO1 extraction. MD optimized TILLING protocol. JS carried out TILLING of RBR. CLS maintained Pisum mutant lines. MS with KT completed HIV-1 quasispecies fingerprinting. $\mathrm{MC}$ and $\mathrm{AB}$ supervised the study. The manuscript was written by KT, JS and AB.

\section{Acknowledgements}

This work was supported by INRA TRANSFERT, Génoplante, the French consortium for plant genomics, GENOPOLE of EVRY and the Grain Legumes Integrated Project (FOOD-CT-2004-506223). Authors would like to thank Pascal Audigier and Julien Martinet for their technical help during this work.

\section{References}

I. Oefner PJ, Underhill PA: Comparative DNA sequencing by denaturing high-performance liquid chromatography (DHPLC). Am J Hum Genet 1995, 57:A266.

2. Orita M, Suzuki Y, Sekiya T, Hayashi K: Rapid and sensitive detection of point mutations and DNA polymorphisms using the polymerase chain reaction. Genomics 1989, 5:874-879.

3. Ganguly A, Rock MJ, Prockop DJ: Conformation-Sensitive Gel Electrophoresis for Rapid Detection of Single- Base Differences in Double-Stranded PCR Products and DNA Fragments: Evidence for Solvent-Induced Bends in DNA Heteroduplexes. PNAS 1993, 90:10325-I0329.

4. Rozycka M, Collins N, Stratton MR, Wooster R: Rapid Detection of DNA Sequence Variants by Conformation-Sensitive Capillary Electrophoresis. Genomics 2000, 70:34-40.

5. Nataraj AJ, Olivos-Glander I, Kusukawa N, Highsmith WE Jr: Singlestrand conformation polymorphism and heteroduplex analysis for gel-based mutation detection. Electrophoresis 1999, 20(6): $1177-1185$.

6. Myers RM, Maniatis T, Lerman LS: Detection and localization of single base changes by denaturing gradient gel electrophoresis. Methods in Enzymology. In Recombinant DNA Part $F$ Volume I55 edition. Edited by: Wu R., Academic Press; 1987:50 I-527.

7. Khrapko K, Hanekamp JS, Thilly WG, Belenkii A, Foret F, Karger BL: Constant denaturant capillary electrophoresis (CDCE): a high resolution approach to mutational analysis. Nucl Acids Res 1994, 22:364-369.

8. Hsia AP, Wen TJ, Chen H, Liu Z, Yandeau-Nelson M, Wei Y, Guo L, Schnable $P$ : Temperature gradient capillary electrophoresis (TGCE), a tool for the high-throughput discovery and mapping of SNPs and IDPs. TAG Theoretical and Applied Genetics 2005, III:218-225.

9. Bui CT, Rees K, Lambrinakos A, Bedir A, Cotton RG: Site-selective reactions of imperfectly matched DNA with small chemical molecules: applications in mutation detection. Bioorg Chem 2002, 30:216-232.

10. Taylor GR, Deeble J: Enzymatic methods for mutation scanning. Genetic Analysis: Biomolecular Engineering 1999, I4:181-186.

II. Howard JT, Ward J, Watson JN, Roux KH: Heteroduplex cleavage analysis using SI nuclease. Biotechniques 1999, 27:18-19.

12. Dodgson JB, Wells RD: Action of single-strand specific nucleases on model DNA heteroduplexes of defined size and sequence. Biochemistry 1977, 16:2374-2379.

13. Yeung AT, Hattangadi D, Blakesley L, Nicolas E: Enzymatic mutation detection technologies. Biotechniques 2005, 38:749-758.

14. Yang B, Wen X, Kodali NS, Oleykowski CA, Miller CG, Kulinski J, Besack D, Yeung JA, Kowalski D, Yeung AT: Purification, cloning, and characterization of the CEL I nuclease. Biochemistry 2000, 39:3533-354I.

15. Colbert T, Till B], Tompa R, Reynolds S, Steine MN, Yeung AT, McCallum CM, Comai L, Henikoff S: High-throughput screening for induced point mutations. Plant Physiol 200 I, I 26:480-484.

16. Bentley A, MacLennan B, Calvo J, Dearolf CR: Targeted recovery of mutations in Drosophila. Genetics 2000, I 56:1169-II 73.

17. Coghill EL, Hugill A, Parkinson N, Davison C, Glenister P, Clements S, Hunter J, Cox RD, Brown SD: A gene-driven approach to the identification of ENU mutants in the mouse. Nat Genet 2002, 30:255-256.

18. Perry JA, Wang TL, Welham TJ, Gardner S, Pike JM, Yoshida S, Parniske M: A TILLING reverse genetics tool and a web-accessible collection of mutants of the legume Lotus japonicus. Plant Physiol 2003, 131:866-871. 
19. Wienholds E, van Eeden F, Kosters M, Mudde J, Plasterk RH, Cuppen E: Efficient target-selected mutagenesis in zebrafish. Genome Res 2003, 13:2700-2707.

20. Till BJ, Burtner C, Comai L, Henikoff S: Mismatch cleavage by single-strand specific nucleases. Nucleic Acids Res 2004, 32:2632-264l.

21. Slade AJ, Fuerstenberg SI, Loeffler D, Steine MN, Facciotti D: A reverse genetic, nontransgenic approach to wheat crop improvement by TILLING. Nat Biotechnol 2005, 23:75-8I

22. Comai L, Young K, Till BJ, Reynolds SH, Greene EA, Codomo CA Enns LC, Johnson JE, Burtner C, Odden AR, Henikoff S: Efficient discovery of DNA polymorphisms in natural populations by Ecotilling. Plant J 2004, 37:778-786.

23. Oleykowski CA, Bronson Mullins CR, Godwin AK, Yeung AT: Mutation detection using a novel plant endonuclease. Nucleic Acids Res 1998, 26:4597-4602.

24. Kulinski J, Besack D, Oleykowski CA, Godwin AK, Yeung AT: CEL I enzymatic mutation detection assay. Biotechniques 2000, 29:44-6, 48.

25. Gerhardus A, Schleberger H, Schlegelberger B, Gadzicki D: Diagnostic accuracy of methods for the detection of BRCAI and BRCA2 mutations: a systematic review. Eur J Hum Genet 2007 1 5:619-627.

26. Sinnett D, Beaulieu P, Belanger $H$, Lefebvre JF, Langlois $S$, Theberge MC, Drouin S, Zotti C, Hudson TJ, Labuda D: Detection and characterization of DNA variants in the promoter regions of hundreds of human disease candidate genes. Genomics 2006, 87:704-710.

27. Kota R, Wolf M, Michalek W, Graner A: Application of denaturing high-performance liquid chromatography for mapping of single nucleotide polymorphisms in barley (Hordeum vulgare L.). Genome 200I, 44(4):523-528.

28. Qiu P, Shandilya H, D'Alessio JM, O'Connor K, Durocher J, Gerard GF: Mutation detection using Surveyor nuclease. Biotechniques 2004, 36:702-707.

29. Silber JR, Loeb LA: SI nuclease does not cleave DNA at singlebase mis-matches. Biochimica et Biophysica Acta (BBA) - Nucleic Acids and Protein Synthesis 1981, 656:256-264.

30. Triques K, Sturbois B, Gallais S, Dalmais M, Chauvin S, Clepet C, Aubourg S, Rameau C, Caboche M, Bendahmane A: Characterization of Arabidopsis thaliana mismatch specific endonucleases: application to mutation discovery by TILLING in pea. Plant J 2007, 5 I : I | | 6- I I 25.

31. Perez-Amador MA, Abler ML, De Rocher EJ, Thompson DM, van Hoof A, LeBrasseur ND, Lers A, Green PJ: Identification of BFN I, a bifunctional nuclease induced during leaf and stem senescence in Arabidopsis. Plant Physiol 2000, I 22:169-180.

32. Voinnet $O$, Rivas S, Mestre $P$, Baulcombe D: An enhanced transient expression system in plants based on suppression of gene silencing by the pl9 protein of tomato bushy stunt virus. The Plant Journal 2003, 33:949-956.

33. Castoldi E, Rosing J: Factor V Leiden: a disorder of factor $\mathbf{V}$ anticoagulant function. Curr Opin Hematol 2004, I I: |76-|8|.

34. Bertina RM, Koeleman BPC, Koster T, Rosendaal FR, Dirven RJ, de Ronde $\mathrm{H}$, van der Velden PA, Reitsma PH: Mutation in blood coagulation factor $\mathbf{V}$ associated with resistance to activated protein C. Nature 1994, 369:64-67.

35. Menendez-Arias L, Martinez MA, Quinones-Mateu ME, Martinez-Picado J: Fitness variations and their impact on the evolution of antiretroviral drug resistance. Curr Drug Targets Infect Disord 2003, 3:355-371.

36. Spira S, Wainberg MA, Loemba H, Turner D, Brenner BG: Impact of clade diversity on HIV-I virulence, antiretroviral drug sensitivity and drug resistance. I Antimicrob Chemother 2003, 5 I:229-240.

37. Chen R, Quinones-Mateu ME, Mansky LM: Drug resistance, virus fitness and HIV-I mutagenesis. Curr Pharm Des 2004, I 0:4065-4070

38. Lal RB, Chakrabarti S, Yang C: Impact of genetic diversity of HIV-I on diagnosis, antiretroviral therapy \& vaccine development. Indian J Med Res 2005, I 2 I:287-3 I4.

39. Palmer S, Kearney M, Maldarelli F, Halvas EK, Bixby CJ, Bazmi H, Rock D, Falloon J, Davey RT Jr., Dewar RL, Metcalf JA, Hammer S, Mellors JW, Coffin JM: Multiple, Linked Human Immunodeficiency Virus Type I Drug Resistance Mutations in Treatment-Expe- rienced Patients Are Missed by Standard Genotype Analysis. J Clin Microbiol 2005, 43:406-4I3.

40. Halvas EK, Aldrovandi GM, Balfe P, Beck IA, Boltz VF, Coffin JM, Frenkel LM, Hazelwood JD, Johnson VA, Kearney M, Kovacs A, Kuritzkes DR, Metzner KJ, Nissley DV, Nowicki M, Palmer S, Ziermann R, Zhao RY, Jennings CL, Bremer J, Brambilla D, Mellors JW: Blinded, Multicenter Comparison of Methods To Detect a Drug-Resistant Mutant of Human Immunodeficiency Virus Type I at Low Frequency. J Clin Microbiol 2006, 44:26I 2-26I4.

4I. Cai F, Chen H, Hicks CB, Bartlett JA, Zhu J, Gao F: Detection of minor drug-resistant populations by parallel allele-specific sequencing. Nat Meth 2007, 4:123-125.

42. Kozal MJ, Shah N, Shen N, Yang R, Fucini R, Merigan TC, Richman DD, Morris D, Hubbell E, Chee M, Gingeras TR: Extensive polymorphisms observed in HIV-I clade B protease gene using high-density oligonucleotide arrays. Nat Med 1996, 2:753-759.

43. Hoffmann C, Minkah N, Leipzig J, Wang G, Arens MQ, Tebas P, Bushman FD: DNA bar coding and pyrosequencing to identify rare HIV drug resistance mutations. Nucl Acids Res 2007, 35:e9I.

44. McCallum CM, Comai L, Greene EA, Henikoff S: Targeting induced local lesions IN genomes (TILLING) for plant functional genomics. Plant Physiol 2000, I 23:439-442.

45. Till BJ, Reynolds SH, Weil C, Springer N, Burtner C, Young K, Bowers E, Codomo CA, Enns LC, Odden AR, Greene EA, Comai L, Henikoff $S$ : Discovery of induced point mutations in maize genes by TILLING. BMC Plant Biol 2004, 4: 12

46. Slade AJ, Knauf VC: TILLING moves beyond functional genomics into crop improvement. Transgenic Res 2005, I 4: 109-I I 5

47. Park JA, Ahn JW, Kim YK, Kim SJ, Kim JK, Kim WT, Pai HS: Retinoblastoma protein regulates cell proliferation, differentiation, and endoreduplication in plants. The Plant Journal 2005, 42: $153-163$

48. Ebel C, Mariconti L, Gruissem W: Plant retinoblastoma homologues control nuclear proliferation in the female gametophyte. Nature 2004, 429:776-780.

49. Gilchrist EJ, Haughn GW, Ying CC, Otto SP, Zhuang J, Cheung D, Hamberger B, Aboutorabi F, Kalynyak T, Johnson L, Bohlmann J, Ellis B, Douglas C], Cronk QC: Use of Ecotilling as an efficient SNP discovery tool to survey genetic variation in wild populations of Populus trichocarpa. Molecular Ecology 2006, I 5(5): | 367-I 378.

50. Till BJ, Zerr T, Bowers E, Greene EA, Comai L, Henikoff S: Highthroughput discovery of rare human nucleotide polymorphisms by Ecotilling. Nucl Acids Res 2006, 34:e99.

5I. Bentley DR: Whole-genome re-sequencing. Current Opinion in Genetics \& Development Genomes and evolution 2006, 16:545-552.

52. Rameau C, Bodelin C, Cadier D, Grandjean O, Miard F, Murfey IC: New ramosus mutants at loci Rms I, Rms 3 and Rms 4 resulting from the mutation breeding program at Versailles. Pisum genetics 1997, 29:7-12.

53. Bendahmane A, Querci M, Kanyuka K, Baulcombe DC: Agrobacterium transient expression system as a tool for the isolation of disease resistance genes: application to the Rx2 locus in potato. Plant J 2000, 2 I:73-8I.

54. Taylor NE, Greene EA: PARSESNP: a tool for the analysis of nucleotide polymorphisms. Nucl Acids Res 2003, 3 I:3808-38 I I.

Publish with Bio Med Central and every scientist can read your work free of charge

"BioMed Central will be the most significant development for disseminating the results of biomedical research in our lifetime. "

Sir Paul Nurse, Cancer Research UK

Your research papers will be:

- available free of charge to the entire biomedical community

- peer reviewed and published immediately upon acceptance

- cited in PubMed and archived on PubMed Central

- yours - you keep the copyright
BioMedcentral 